\title{
Astrocytes: Role and Functions in Brain Pathologies
}

\author{
Rosalba Siracusa ${ }^{1 t}$, Roberta Fusco ${ }^{1 \dagger}$ and Salvatore Cuzzocrea ${ }^{1,2 *}$ \\ ${ }^{1}$ Department of Chemical, Biological, Pharmaceutical and Environmental Science, University of Messina, Messina, Italy, \\ ${ }^{2}$ Department of Pharmacological and Physiological Science, Saint Louis University School of Medicine, Saint Louis, MO, \\ United States
}

Astrocytes are a population of cells with distinctive morphological and functional characteristics that differ within specific areas of the brain. Postnatally, astrocyte progenitors migrate to reach their brain area and related properties. They have a regulatory role of brain functions that are implicated in neurogenesis and synaptogenesis, controlling blood-brain barrier permeability and maintaining extracellular homeostasis. Mature astrocytes also express some genes enriched in cell progenitors, suggesting they can retain proliferative potential. Considering heterogeneity of cell population, it is not surprising that their disorders are related to a wide range of different neuro-pathologies. Brain diseases are characterized by the active inflammatory state of the astrocytes, which is usually described as up-regulation of glial fibrillary acidic protein (GFAP). In particular, the loss of astrocytes function as a result of cellular senescence could have implications for the neurodegenerative disorders, such as Alzheimer disease and Huntington disease, and for the aging brain. Astrocytes can also drive the induction and the progression of the inflammatory state due to their $\mathrm{Ca}^{2+}$ signals and that it is strongly related to the disease severity/state. Moreover, they contribute to the altered neuronal activity in several frontal cortex pathologies such as ischemic stroke and epilepsy. There, we describe the current knowledge pertaining to astrocytes' role in brain pathologies and discuss the possibilities to target them as approach toward pharmacological therapies for neuro-pathologies.

Keywords: astrocytes, Alzheimer disease, Huntington disease, epilepsy, ischemic stroke, drug

\section{INTRODUCTION}

During development, radial glial cells are the primary neural stem cells developing all neurons such as astrocytes, microglia cells, ependymal cells, and oligodendrocytes (Taverna et al., 2014). Mature astrocytes are categorized for functional and morphology proprieties. In the frontal cortex, these cells can be morphologically distinguished in four types: fibrous astroglia, protoplasmic, varicose, and interlaminar projections placed in the white matter and I, II, III, IV, V, and VI layers (Vasile et al., 2017). Other functional and morphological distinct astrocytes are unipolar Bergmann glia with radial ascending processes and elongated radial glia-like tanycytes. In the cerebellum, Bergmann glia control the synapsis of Purkinje cells (De Zeeuw and Hoogland, 2015), while in the hypothalamus, tanycytes are specialized in the modulation of neuroendocrine functions (Prevot et al., 2018). One of the most important astrocytes function is to deliver energy to neurons by the astrocyte-neuron lactate shuttle (Bass et al., 1971; Sherwood et al., 2006). Astrocytes modulate $\mathrm{Ca}^{2+}$ variations that influence neuronal activity releasing gliotransmitters (Peteri et al., 2019). 
The modulation of the neurotransmitter uptake involves the excitatory transporters 1 and 2 (EAAT1 and 2) (Roberts et al., 2014). In response to inflammation and injury, astrocytes become reactive. They can be divided in two main categories: scar-forming astrocytes and hypertrophic astrocytes (Khakh et al., 2017). Several studies underline that reactive astrocytes alter them homeostatic functions such as potassium ion uptake, ion buffering, $\mathrm{Ca}^{2+}$ signaling, and excitatory neurotransmitter uptake (Rossi and Volterra, 2009). Regulation of astrocytes functions affected several brain pathologies such as Alzheimer disease, Huntington disease, Ischemic stroke, and epilepsy.

\section{ALZHEIMER DISEASE}

$\mathrm{AD}$ is a neurodegenerative disease with motor abnormalities, cognitive changes, and behavioral impairment. It is characterized by the aggregation of amyloid- $\beta$ plaques in vessel walls and accumulation of the protein tau in neural cells. Astrocytes in this pathology contribute to the loss of neuroprotection and to the gaining of pathological characteristics. At the beginning, astrocytes have a protective role up-taking and degrading amyloid- $\beta$. The progression of disease leads to reduced astrocyte clearance of amyloid- $\beta$ that contribute to gain of function (Garwood et al., 2017). Furthermore, amyloid- $\beta$ accumulation stimulates astrocytes to produce pro-inflammatory mediators inducing a positive feedback of activation (González-Reyes et al., 2017).

It has been shown that amyloid- $\beta$ co-operates with several receptors located on astrocytes such as scavenger receptors, TLRs, lipoprotein, glycoprotein and acetylcholine receptors, chemokine, and complement receptors (Farfara et al., 2008). Scavenger receptors are a group of evolutionally conserved membrane receptors expressed on the surface of microglia, macrophages, and dendritic cells (Wilkinson and El Khoury, 2012). To date, they have been classified into six classes (scavenger receptor $\mathrm{A}, \mathrm{B}, \mathrm{C}, \mathrm{D}, \mathrm{E}$, and $\mathrm{F}$ ) even if some members of this family remain unclassified (RAGE, CD163, and SR-PSOX). Of particular interest during $\mathrm{AD}$ are CD36, RAGE (receptor for advanced glycation end products), SCARA-1 (scavenger receptor A-1), and MARCO (macrophage scavenger receptor with collagenous structure). SCARA-1 is involved in clearance of A $\beta$, while MARCO forms a complex with formyl peptide-receptorlike 1 (FPR1) upon encountering A $\beta$. MARCO may decrease the inflammatory response in microglia through the FPR-1 via the ERK 1/2 intracellular signaling and the inhibition of cAMP (Brandenburg et al., 2010). CD36 and RAGE are implicated in activation of microglia by $\mathrm{A} \beta$. CD36 cooperates with the other innate immune pattern recognition receptor like the TLRs to outline pathogen-specific responses. Once engaged by A $\beta, \mathrm{CD} 36$ forms a complex with TLR- 6 and TLR- 4 causing ROS production and inflammasome activation (Stewart et al., 2010). RAGE receptor is one of the most characterized unclassified scavenger receptor and has been reported to produce proinflammatory modifications in astrocytes when binds amyloid- $\beta$ (GonzálezReyes et al., 2017). RAGE in turn activates the NF-kB (Yan et al., 1994) and its downstream pathway including p21,
Cdc42-Rac, ras, MAPK (Taguchi et al., 2000), ERK (Wilkinson and El Khoury, 2012), and JNK (González-Reyes et al., 2017). RAGE is highly expressed vasculature and neurons in AD brains compared with the un-diseased (Arancio et al., 2004). RAGE located on endothelial cells in implicated in transporting $A \beta$ into the brain (Mackic et al., 1998), and also increasing the diapedesis of monocytes across the blood-brain barrier (Giri et al., 2000). Once bound to soluble $\mathrm{A} \beta$, RAGE induces microglial activation and chemotaxis following a concentration gradient, leading to a microglial accumulation around $A \beta$ plaques (Wilkinson and El Khoury, 2012). RAGE mediates also the phagocytic profile of astrocytes and the interaction with other ligands, including S100 $\beta$, involved in Alzheimer disease neuroinflammation (Cirillo et al., 2015). S100 $\beta$ produced by astrocytes is a common feature of Alzheimer disease (Bosch et al., 2015). It is associated with depressive behavior and cognitive flexibility and regulates neuronal oscillations (Stroth and Svenningsson, 2015; Brockett et al., 2018).

Moreover, morphological modifications of astrocytes in Alzheimer disease involve alterations in $\mathrm{K}^{+}$neurovascular regulation, by downregulation of Kir4.1 and $\mathrm{BK}_{\mathrm{Ca}}$, causing irregular cerebral blood flow (González-Reyes et al., 2017). Also, $\mathrm{Ca}^{2+}$ signaling is altered by amyloid- $\beta$ accumulation (Haughey and Mattson, 2003). In astrocytes, this accumulation modifies the expression of the nicotinic acetylcholine receptors (nAchRs) and metabotropic glutamate receptor 5 (mGluR5), changing $\mathrm{Ca}^{2+}$ homeostasis (Xiu et al., 2005; Lim et al., 2013). Through this pathway, astrocytes increase glutamate signaling and led to the downregulation of its transporters (Masliah et al., 1996). Glutamate aberrant trafficking is linked to the modified cholesterol synthesis (Tian et al., 2010; Merlini et al., 2011; Talantova et al., 2013). A prodromal symptom to Alzheimer's disease can be the glucose hypometabolism (Mosconi et al., 2006). Carriers of apolipoprotein E\&4 (APOE\&4) allele display lower glucose metabolism in different brain area with an augmented risk for AD (Reiman et al., 2004). Astrocytes signaling is a useful target to prevent and control the development of the AD.

\section{HUNTINGTON DISEASE}

Huntington disease is a genetic neurodegenerative disease with neuropsychiatric and motor dysfunctions. It is caused by a trinucleotide repeat (CAG) in the gene for Htt. This expansion caused a different form of $\mathrm{Htt}(\mathrm{mHtt})$ which aggregates (Bunner and Rebec, 2016). Astrocytes are more efficient than neurons in clearance of aggregates, so they are more resistant to $\mathrm{mHtt}$ accumulation (Zhao et al., 2016; Jansen et al., 2017; Zhao et al., 2017). However, when mHtt aggregates into astrocytes modifies glutamate signaling, causing neuronal excitotoxicity (Shin et al., 2005; Bradford et al., 2009). This condition is a typical feature of Huntington disease but has also been described several cases without alteration in glutamate release (Parsons et al., 2016). Astrocytes in Huntington disease are characterized by a decreased expression of Kir4.1 (Tong et al., 2014; Zhang et al., 2018). It influences GLT1-mediated homeostasis and $\mathrm{Ca}^{2+}$ signaling (Tong et al., 2014; Jiang et al., 2016). These dysfunctions 
head the reactive state of astrocytes bringing about the possibility neurotoxicity can induce inflammation as secondary effect of Huntington disease (Tong et al., 2014).

During the inflammatory state, microglia trigger the activation of astrocytes releasing factors such as TNF- $\alpha, \mathrm{C1q}$, and IL-1 $\alpha$ (Khakh and Sofroniew, 2015; Liddelow et al., 2017). They decreased synaptic maintenance and phagocytic activity (Bradford et al., 2009) and increase degeneration neurons and oligodendrocytes (Liddelow et al., 2017).

$\mathrm{mHtt}$ accumulation modifies astrocytes exosome (Hong et al., 2017) and BDNF (Hong et al., 2016) release. Restoration of BDNF expression from astrocytes displays neuroprotective effects (Giralt et al., 2010; Hong et al., 2016; Reick et al., 2016). It has been displayed that astrocytes are intricated in a wide range of pathological features of Huntington disease, so they can be used as a novel therapeutic target.

\section{EPILEPSY}

Epilepsy is a group of brain disorders characterized by unpredictable and periodic occurrence of seizures. The cause of most cases of epilepsy is unknown. Some cases occur as the result of brain injury, stroke, brain tumors, infections of the brain, and birth defects through a process known as epileptogenesis (Goldberg and Coulter, 2013). Known genetic mutations are directly linked to a small proportion of cases (Pandolfo, 2011). Although the symptoms of a seizure may affect any part of the body, the electrical events that produce the symptoms occur in the brain. Epileptic seizures are the result of excessive and abnormal neuronal activity in the cortex of the brain (Fisher et al., 2005).

The most common of these pathologies is the hippocampal sclerosis or mesial temporal sclerosis. It is characterized by gliosis, neuronal cell loss in the hippocampal areas, synaptic reorganization, and microvascular proliferation. A study published in PloS Biology shows how the interaction between neurons and astrocytes is one of the mechanisms that contributes to the generation of epileptic discharges. Believed in the past to be simple "helpers" of neurons, astrocytes have revealed over time cells that play a much more active role in the brain (Gomez-Gonzalo et al., 2010). Astrocytes express ion channels, transmitter receptors, and transporters and, thus, are endowed with the machinery to sense and respond to neuronal activity. Glutamate transporters are located on several neuronal cell types, but astrocytes are mainly involved in the glutamate uptake (Steinhauser et al., 2016). GLT-1, the glutamate transporter located on astrocytes, is involved in the bulk of extracellular glutamate clearance and is responsible of the increased levels in epileptogenic foci. Moreover, glutamine synthetase is reduced in the hippocampus of temporal lobe epilepsy patients compared to the healthy one. This downregulation leads to a slow glutamate-glutamine cycling and an accumulation of the transmitter in the extracellular space and astrocytes, providing a metabolic mechanism for astrocyte-dependent hyperexcitability. A few studies have highlighted the contribution of ionotropic glutamate receptors in convulsion generation. AMPA receptors, in particular the subtype composed by subunits GluR1 to GluR4, are abundantly expressed on astrocytes. Epilepsy patients show an enhanced expression of GluR1 flip variants accounts for the prolonged receptor in hippocampal astrocytes. Prolonged receptor opening increases influx of $\mathrm{Na}^{+}$and $\mathrm{Ca}^{2+}$ ions, blocking astroglial Kir channels which increase depolarization reducing the $\mathrm{K}^{+}$buffering capacity of astrocytes (Steinhauser et al., 2012). All this process contributes to hyperexcitability. In this condition, extracellular $\left[\mathrm{K}^{+}\right]$could increase from $\sim 3 \mathrm{mM}$ to $10-12 \mathrm{mM}$; and glial cells take the most $\mathrm{K}^{+}$released by active neurons. As already mentioned, the primary mechanism for spatial $\mathrm{K}^{+}$buffering and $\mathrm{K}^{+}$reuptake is via glial inwardly rectifying $\mathrm{K}^{+}$channels (Kir channels). Kir channel subtypes (Kir1-Kir7) differ in functional properties and tissue distribution; Kir4.1 is the most abundantly in brain astrocytes. Astrocytes are also joined by gap junctions, which allow these cells to redistribute through the glial network the $\mathrm{K}^{+}$ions excessively accumulated at sites of intense neuronal activity. Accordingly, increasing evidence indicates that dysfunctional astrocytes are crucially involved in processes leading to epilepsy (Steinhauser and Seifert, 2012).

\section{ISCHEMIC STROKE}

Ischemic stroke is a brain damage which can lead to death or disabilities. It results from a vasculature dysfunction with occlusion of blood vessels by embolus or thrombus. The reduced or blocked blood flow causes loss of oxygen and glucose and in turn synthesis of ATP via glycolysis and oxidative phosphorylation. These conditions produce excitotoxicity and malfunction of astrocytes glutamate transporters, fundamental in the synaptic cleft in clearing glutamate release (Yi and Hazell, 2006; Zou et al., 2010). Increased glutamate release in the extracellular area induces the overexpression of rNMDARs and caused overloading of intracellular $\mathrm{Ca}^{2+}$ (Tanaka et al., 1997; Medvedeva et al., 2009). This energy depletion influences membrane potential depolarization and ionic gradients in neurons and astrocytes. In particular, astrocytes, comparing neurons, are less susceptible to glutamate cytotoxicity induced by brain stroke, but they display proliferation and up-regulation of GFAP levels producing reactive astrogliosis (Sofroniew, 2000). Reactive astrocytes are usually found in the focal lesions with tissues reorganization and formation of glial scars (Sofroniew, 2000). White matter astrocytes are especially sensible to ischemic stroke (Chen et al., 2016). The ischemic core shows a predominant presence of hypertrophic astrocytes with a larger $\mathrm{Ca}^{2+}$ signal compared to the penumbra region, the area surrounding the ischemic locus (Ding et al., 2009). Transcriptome analysis of activated astrocytes from inflamed brain after middle cerebral artery occlusion shows expression of genes encoding neuroprotective mediators and included cytokines (IL-6, IL-1, IL-1 $\beta$, IL-10), transforming growth factor- $\beta$ (TGF $\beta$ ), interferon- $\gamma$ (IFN- $\gamma$ ), thrombospondins, and neurotrophic factors (Zamanian et al., 2012). High levels of cytokines induce increasing levels of nitric oxide (NO) (Stoll et al., 1998) and apoptosis of neuronal cells (Clark and Lutsep, 2001) and inhibit neurogenesis (Monje et al., 2003). Reactive astrocytes also release chemokines after ischemia (Kim, 1996). In vascular endothelial cells, chemokines increased 
adhesion molecules levels, attracting immune cells (Sofroniew, 2000). Astrocytes are the first cells of the nervous system where the class II major histocompatibility complex (MHC) (Dong and Benveniste, 2001) was shown. MHC II presents antigens to CD41 T-helper cells and is expressed on antigen presenting cells (APCs). Moreover, astrocytes express pattern recognition receptors (PRRs) as scavenger receptor, TLRs, and complement proteins playing a role in immune response regulation (Bsibsi et al., 2006).

These features let us to consider astrocyte a possible regulator of the ischemic context, considering that chronic of inflammation is influenced by the degree of tissue injury and exacerbation of the damage.

\section{DISCUSSION}

To date, only five drugs are accepted by the Food and Drug Administration (FDA) for the cure of AD: donepezil, galantamine and rivastigmine, memantine, and a drug composed of donezil and memantine (Table 1). Unfortunately, the use of these drugs is aimed at improving the excellence of life of patients, and they are not capable to stop the progression of the disorder (Caselli et al., 2017). So, it is important to find innovative treatments that improve therapeutic results. $A \beta$ plaques increase the proinflammatory cytokines (Patel et al., 2005; Colombo and Farina, 2016) and the production of free radicals (Carson et al., 2006; Wyss-Coray and Rogers, 2012) with consequent activation of the astrocytes. In a late study conducted on APP/ PS1 transgenic mice and on mixed neuronal/glial cultures, it was shown that curcumin improves spatial memory, stimulates cholinergic neuronal function, and, through PPAR- $\gamma$, reduces the activation of the inflammatory process in microglia and astrocytes (González-Reyes et al., 2017). Additional natural phytochemicals have demonstrated an anti-inflammatory and immunosuppressive capacities in $\mathrm{AD}$ models (Table 1), e.g., the triptolide extract inhibits astrocyte activation in the APP/PS1 transgenic mouse model of AD (Li et al., 2016). Punicalagin, a pomegranate derivative, reduces neuroinflammation (lowering TNF- $\alpha$ and IL- $\beta$ ) and also prevents oxidative stress by reducing iNOS, COX-2, and ROS production (Kim et al., 2017). Other mixtures that may have a probable role against dementia (Libro et al., 2016) are cannabinoid agonists such as WIN, 2-AG, and methanandamide (Table 1) that have shown anti-inflammatory activities in primary astrocytes grown later exposure to $A \beta_{1-42}$ or $\mathrm{A} \beta_{25-35}$ (Aguirre-Rueda et al., 2015; Gajardo-Gomez et al., 2017). Other approaches to diminish oxidative stress in AD models involve stimulants of endogenous antioxidant factors (Table 1) such as pelargonidine (Sohanaki et al., 2016), Bambusae concretio Silicea (Jeong et al., 2005), and the new compound Monascin (Shi et al., 2016). In in vivo and in in vitro analyses, it has been shown that exogenous antioxidant compounds (Table 1) also have beneficial effects. Among these, we have resveratrol (Wang et al., 2016), tocotrienol (vitamin E) (Ibrahim et al., 2017), anthocyanins (Rehman et al., 2017), epicatechin (Cuevas et al., 2009), and 3H-1,2-dithiole-3-thione (a powerful free radical scavenger) (Wang et al., 2017). A $\beta$ accumulation from astrocytes can also be decreased using IL- $1 \beta$ or TNF- $\alpha /$ TNF- $\alpha$, PPAR- $\gamma$
TABLE 1 | Neurologically active drugs.

\begin{tabular}{|c|c|c|}
\hline Disease & Drug category & References \\
\hline \multirow[t]{7}{*}{$A D$} & FDA accepted & $\begin{array}{l}\text { Donepezil, galantamine, rivastigmine, } \\
\text { memantine, and donezil + memantine } \\
\text { (Caselli et al., 2017) }\end{array}$ \\
\hline & $\begin{array}{l}\text { Natural } \\
\text { phytochemicals }\end{array}$ & $\begin{array}{l}\text { Triptolide extract (Li et al., 2016) and } \\
\text { punicalagin (Kim et al., 2017) }\end{array}$ \\
\hline & Cannabinoid agonists & $\begin{array}{l}\text { WIN, 2-AG, and methanandamide } \\
\text { (Aguirre-Rueda et al., 2015; Gajardo- } \\
\text { Gomez et al., 2017) }\end{array}$ \\
\hline & $\begin{array}{l}\text { Endogenous } \\
\text { antioxidant factors }\end{array}$ & $\begin{array}{l}\text { Pelargonidine (Sohanaki et al., 2016), } \\
\text { Bambusae concretio Salicea (Jeong } \\
\text { et al., 2005), monascin (Shi et al., } \\
\text { 2016) }\end{array}$ \\
\hline & $\begin{array}{l}\text { Exogenous antioxidant } \\
\text { compounds }\end{array}$ & $\begin{array}{l}\text { Resveratrol (Wang et al., 2016), } \\
\text { tocotrienol (lbrahim et al., 2017), } \\
\text { anthocyanins (Rehman et al., 2017), } \\
\text { epicatechin (Cuevas et al., 2009), } \\
\text { and } 3 \mathrm{H}-1,2 \text {-dithiole-3-thione (Wang } \\
\text { et al., 2017) }\end{array}$ \\
\hline & $\begin{array}{l}\text { Stimulators of the } \\
\text { GLT1 expression }\end{array}$ & $\begin{array}{l}\text { Penicillin, cephalosporin, ampicillin, } \\
\text { estrogen, riluzole, and insulin (Frizzo } \\
\text { et al., 2004; Brann et al., 2007; Ji } \\
\text { et al., 2011) }\end{array}$ \\
\hline & $\begin{array}{l}\text { Activators of the GLT1 } \\
\text { translation } \\
\text { GABA receptor } \\
\text { antagonists }\end{array}$ & $\begin{array}{l}\text { Pyridazine and LDN/OSU-0212320 } \\
\text { (Colton et al., 2010; Xing et al., 2011) } \\
\text { (Yuan and Shan, 2014) }\end{array}$ \\
\hline \multirow[t]{3}{*}{ Epilepsy } & AED & $\begin{array}{l}\text { Valproic acid, lamotrigine, } \\
\text { phenobarbital, gabapentin, felbamate, } \\
\text { and topiramate (French and Gazzola, } \\
\text { 2011) }\end{array}$ \\
\hline & Anticancer drug & $\begin{array}{l}\text { Rapamycin (Huang et al., 2010; Kim } \\
\text { and Lee, 2019) }\end{array}$ \\
\hline & $\begin{array}{l}\text { Allosteric potentiators } \\
\text { of glutamine } \\
\text { synthetase, } \\
\text { regulators of AQP4 } \\
\text { trafficking, interleukin } \\
1 \text { antagonists, and } \\
\text { agonists or allosteric } \\
\text { potentiators of TNFR2 }\end{array}$ & $\begin{array}{l}\text { (Wetherington et al., 2008) (Crunelli } \\
\text { et al., 2015) }\end{array}$ \\
\hline \multirow{4}{*}{$\begin{array}{l}\text { Ischemic } \\
\text { stroke }\end{array}$} & Stimulators of the & Ceftriaxone (Ouyang et al., 2007; \\
\hline & GLT1 expression & $\begin{array}{l}\text { Verma et al., 2010), carnosine (Shen } \\
\text { et al., 2010), and tamoxifen (Lee } \\
\text { et al., 2009) }\end{array}$ \\
\hline & $\begin{array}{l}\text { Inhibitors of p53 } \\
\text { activity }\end{array}$ & $\begin{array}{l}\text { MicroRNA-29a (Ouyang et al., 2013; } \\
\text { Ouyang et al., 2014) }\end{array}$ \\
\hline & $\begin{array}{l}\text { Stimulators of } \\
\text { angiogenesis }\end{array}$ & $\begin{array}{l}\text { Ecdysterone (Luo et al., 2011) and } \\
\text { omega-3 polyunsaturated fatty acids } \\
\text { (Wang et al., 2014) }\end{array}$ \\
\hline
\end{tabular}

receptor agonists, minocycline or nicergoline, and tyrosine kinase inhibitors (Von Bernhardi et al., 2010; Kitazawa et al., 2011; Mandrekar-Colucci et al., 2012; Tweedie et al., 2012). NSAIDs are drugs that bind to and activate the PPAR- $\gamma$ receptor (Jaradat et al., 2001; Wick et al., 2002) leading to reduced activation of glial cells (Combs et al., 2000; Bernardo and Minghetti, 2006) and cytokine-mediated inflammation (Sastre and Gentleman, 2010; De Nuccio et al., 2015).

The astrocyte carries most of the extracellular glutamate. Therefore, damage to astrocytes affects their capability to perceive or respond to an increase in glutamate levels which leads to the 
destruction of the microenvironment near neurons causing an over-stimulation of NMDA receptors, responsible for changes in cognitive functions in the frontal cortex (Finsterwald et al., 2015). Current studies have shown that the damage to astrocytes induced by $A \beta$ is responsible for the reduced expression of GLT1 in AD. Therefore, drugs that target astrocytic glutamate transporters to ameliorate their expression and role represent a possible target for neurodegenerative syndromes. In this regard, there are two pharmacological approaches to increase GLT expression: either by increasing GLT1 promoter activation or by activating GLT1 translation (Rothstein et al., 2005; Kong et al., 2014). Among the compounds able to stimulate the expression of GLT1 already $48 \mathrm{~h}$ after drug treatment, there are $\beta$-lactam antibiotics comprising penicillin and its derivatives, as well as cephalosporin antibiotics. Other mixtures such as ampicillin, estrogen, riluzole, and insulin have also been found to increase GLT1 expression (Frizzo et al., 2004; Brann et al., 2007; Ji et al., 2011) (Table 1). Instead, among compounds that have been found to activate the GLT1 translation (Table 1), we have a series of compounds based on pyridazine and LDN/OSU-0212320 (Colton et al., 2010; Xing et al., 2011). Finally, recent studies have correlated GABAergic neurotransmission with the pathological changes of AD (Li et al., 2011). Damaged astrocytes produce a copious amount of GABA that is released to inhibit excitatory neurotransmission in the dentate gyrus. In addition to GABA, monoamine oxidase-B (MAO-B) has been reported to be altered on reactive astrocytes (Jo et al., 2014), and the enzyme is upregulated in the post mortem brain of individuals with AD (Saura et al., 1994). In an animal model of Alzheimer, it has been shown that the administration of GABA receptor antagonists (Table 1) improve long-term memory in the hippocampus (Yuan and Shan, 2014).

$\mathrm{HD}$ is a disease that progressively destroys neurons in the brain and leads to severe motor and cognitive deficits. To date, no cure is available, but researchers have made progress that can lead to effective therapies. Numerous studies suggest that astrocytes may be intricated in HD. In particular, it has been observed that mHTT accumulations in striatal astrocytes are present in the brains of HD patients and in HD mouse models (Bradford et al., 2009). Several HD mouse models have been used to evaluate the contribution of astrocytes to HD pathophysiology. In one of these studies, astrogliosis was evaluated as it frequently accompanies brain disorders. In conjunction with the start of symptoms, a high number of astrocytes showed mHTT inclusions and an important reduction in fundamental functional proteins. One of these proteins was Kir4.1 (Tong et al., 2014). These results propose that mHTT is correlated with early termination of the expression of essential functional astrocyte proteins (e.g., Kir4.1), which modifies the function of astrocytes without triggering astrogliosis. Furthermore, striatal astrocytes of HD mice show depolarized membrane potentials and lower membrane conductances when mice are symptomatic. This is owing to the function and lower expression of the Kir4.1 channels. Deficiencies in latent membrane potential were recovered by selective release of Kir4.1 from adeno-associated viruses (AAV) and a specific astrocyte promoter. Furthermore, it has been observed that the loss of Kir4.1 currents in striatal astrocytes leads to reduced $\mathrm{K}^{+}$spatial buffering, which leads to higher environmental $\mathrm{K}^{+}$levels in HD mouse models. Therefore, the astrocytic channels Kir.4.1, and other astrocytic molecular mechanisms can represent appreciated targets for therapeutic development (Khakh and Sofroniew, 2014).

Other approaches currently being studied for HD therapy point to both to obtain information on the mechanisms of disease progression and to silence the expression of mHTT using antisense oligonucleotides. A new approach is to detect novel factors that increase neurogenesis and/or stimulate the reprogramming of endogenous neuroblasts and parenchymal astrocytes to produce new healthy neurons to substitute the lost ones and/or strengthen the neuroprotection of preexisting striatal and cortical neurons (Sassone et al., 2018).

Regarding epilepsy, to date, more than 20 antiepileptic drugs (AEDs) (Table1) have been developed, including valproic acid, lamotrigine, phenobarbital, gabapentin, felbamate, and topiramate (French and Gazzola, 2011). Despite this, 30\% of patients respond poorly to treatment (Kwan and Brodie, 2000). In contrast, $70 \%$ of patients can attain long-term remission under AED treatment. However, many AEDs are associated with adverse side effects that are experienced by a substantial number of patients. Thus, significant unmet medical needs still must be overcome for the real and safe treatment of epilepsy. Many studies have suggested that inequities between excitatory and inhibitory signals may cause epilepsy (White et al., 2007; Bialer and White, 2010). AEDs currently used to stop epileptic seizures act mostly by blocking ion channels and inhibiting neuronal excitability. Rapamycin, which was approved by the FDA as an anticancer drug (Table 1), has been demonstrated as another potential antiepileptic agent with broader clinical relevance (Huang et al., 2010; Kim and Lee, 2019). Unfortunately, rapamycin can inhibit cell proliferation and motility; thus, the safety of long-term rapamycin treatments must be assessed in advance. However, the role of the mTOR inhibition strategy for the treatment of epilepsy remains viable (Russo et al., 2014). Today, it is clear that astrocytes play prominent roles in information processing in the epileptic brain. Insights gleaned from careful studies of the properties of reactive astrocytes suggest several novel targets for drug development (Table 1), including allosteric potentiators of glutamine synthetase, regulators of AQP4 trafficking, interleukin 1 antagonists, and agonists or allosteric potentiators of TNFR2 (Wetherington et al., 2008) (Crunelli et al., 2015).

To date, pharmacological treatments for ischemia/ reperfusion have palliative effects and require almost immediate administration after damage (Van Der Worp and Van Gijn, 2007). To overcome this problem, it is indispensable to find new treatments focused mainly on long-term neuroprotection. Strategies targeting astrocytes may be an option as the increase in astrocyte survival during ischemic stress is connected with increased neuronal survival. It has been observed that induction of glial-specific purinergic receptor activation (P2Y1R) leads to greater consumption of mitochondrial $\mathrm{O}_{2}$ and stimulation of ATP production by astrocytes thus reducing neuronal damage to astrocytes and cell death and therefore brain damage (Zheng et al., 2013; Liu and Chopp, 2016). Furthermore, infarct area improved even after administration of TGF- $\alpha$ (Sharif et al., 2007). This treatment also led to a significant functional recovery 
in rats after MCAO (Justicia et al., 2001). Other experiments indicate that another therapeutic potential involves the increase in astrocytic glutamate transport after stroke. Thus, the increased expression of the glutamate transporter GLT-1 in astrocytes with ceftriaxone (Table 1) (Ouyang et al., 2007; Verma et al., 2010) protects neurons from ischemia (Chu et al., 2007). Other compounds that improve neurological function and reduce the infarct area are carnosine (Shen et al., 2010) and tamoxifen (Lee et al., 2009) (Table 1). Both substances preserve the expression of GLT-1 on astrocytes by reducing glutamate levels and attenuating the consequent excitotoxicity. Another target for stroke therapy is p53 (Table 1) since inhibition of p53 activity has been shown to hinder astrocyte activation and glutamate intake (Ahn et al., 2015). Even microRNAs, approximately of which are expressed in astrocytes as microRNA-29a, appear to be intricate in the control of cerebral ischemia and may represent targets for improving stroke outcome (Ouyang et al., 2013; Ouyang et al., 2014). More recently, reference is made to cell therapy which aims at finding cells that can induce regeneration. Astrocyte transplantation conducts to recovery of axonal myelination, variation of the immune response, and issue of neurotrophic factors that prevent oxidative stress and excitotoxic injury (Choudhury and Ding, 2016). Other studies have suggested to astrocytes a therapeutic target based on their control by genetic change of proteins associated to the immune response and exacerbation of reactivity and cytotoxicity (Merienne et al., 2015). Finally, it was observed

\section{REFERENCES}

Aguirre-Rueda, D., Guerra-Ojeda, S., Aldasoro, M., Iradi, A., Obrador, E., Mauricio, M. D., et al. (2015). WIN 55,212-2, agonist of cannabinoid receptors, prevents amyloid beta1-42 effects on astrocytes in primary culture. PLoS One 10, e0122843. doi: 10.1371/journal.pone.0122843

Ahn, K. C., Mackenzie, E. M., Learman, C. R., Hall, T. C., Weaver, C. L., Dunbar, G. L., et al. (2015). Inhibition of p53 attenuates ischemic stress-induced activation of astrocytes. Neuroreport 26, 862-869. doi: 10.1097/WNR.0000000000000439

Arancio, O., Zhang, H. P., Chen, X., Lin, C., Trinchese, F., Puzzo, D., et al. (2004). RAGE potentiates $A \beta$-induced perturbation of neuronal function in transgenic mice. EMBO J. 23, 4096-4105. doi: 10.1038/sj.emboj.7600415

Bass, N. H., Hess, H. H., Pope, A., and Thalheimer, C. (1971). Quantitative cytoarchitectonic distribution of neurons, glia, and $\mathrm{DNa}$ in rat cerebral cortex. J. Comp. Neurol. 143, 481-490. doi: 10.1002/cne.901430405

Bernardo, A., and Minghetti, L. (2006). PPAR-gamma agonists as regulators of microglial activation and brain inflammation. Curr. Pharm. Des. 12, 93-109. doi: $10.2174 / 138161206780574579$

Bialer, M., and White, H. S. (2010). Key factors in the discovery and development of new antiepileptic drugs. Nat. Rev. Drug Discov. 9, 68-82. doi: 10.1038/ $\operatorname{nrd} 2997$

Bosch, M. N., Pugliese, M., Andrade, C., Gimeno-Bayón, J., Mahy, N., and Rodriguez, M. J. (2015). Amyloid- $\beta$ immunotherapy reduces amyloid plaques and astroglial reaction in aged domestic dogs. Neurodegener. Dis. 15, 24-37. doi: 10.1159/000368672

Bradford, J., Shin, J.-Y., Roberts, M., Wang, C.-E., Li, X.-J., and Li, S. (2009). Expression of mutant huntingtin in mouse brain astrocytes causes agedependent neurological symptoms. Proc. Natl. Acad. Sci. 106, 22480-22485. doi: 10.1073/pnas.0911503106

Brandenburg, L. O., Konrad, M., Wruck, C. J., Koch, T., Lucius, R., and Pufe, T. (2010). Functional and physical interactions between formyl-peptide-receptors and scavenger receptor MARCO and their involvement in amyloid beta 1-42-induced signal transduction in glial cells. J. Neurochem. 113, 749-760. doi: $10.1111 /$ j.1471-4159.2010.06637.x that post-stroke angiogenesis not only ameliorate blood perfusion in the ischemic area but also supports cerebral parenchymal cells, comprising astrocytes, the issue of neurotrophic factors, to stimulate neurogenesis, which therefore improves remodeling cerebral and long-term neurological function after stroke (Zhang and Chopp, 2009). Consequently, angiogenesis represents a valid reparative machinery that has been verified in numerous studies (Table 1). For example, treatment with ecdysterone ameliorates neurological function by improving astrocyte stimulation and angiogenesis after focal cerebral ischemia in rats (Luo et al., 2011). Transgenic overproduction of omega-3 polyunsaturated fatty acids in mice recovers post-stroke revascularization and increases endogenous angiogenesis by inducing angiopoietin 2 production in astrocytes, which consequently stimulated endothelial cell proliferation and BBB formation, proposing that the integration of omega-3 polyunsaturated fatty acids is a possible angiogenic treatment able to increase brain repair and improve long-term functional recovery after ischemic stroke (Wang et al., 2014).

\section{AUTHOR CONTRIBUTIONS}

RS and RF made literature search and wrote the first draft of the manuscript. SC, RS and RF designed the aim of the review. All authors contributed to reading and approving the final version of the manuscript.

Brann, D. W., Dhandapani, K., Wakade, C., Mahesh, V. B., and Khan, M. M. (2007). Neurotrophic and neuroprotective actions of estrogen: basic mechanisms and clinical implications. Steroids 72, 381-405. doi: 10.1016/j. steroids.2007.02.003

Brockett, A. T., Kane, G. A., Monari, P. K., Briones, B. A., Vigneron, P.-A., Barber, G. A., et al. (2018). Evidence supporting a role for astrocytes in the regulation of cognitive flexibility and neuronal oscillations through the Ca2+ binding protein S100ß. PloS One 13, e0195726. doi: 10.1371/journal. pone. 0195726

Bsibsi, M., Persoon-Deen, C., Verwer, R. W. H., Meeuwsen, S., Ravid, R., and Van Noort, J. M. (2006). Toll-like receptor 3 on adult human astrocytes triggers production of neuroprotective mediators. Glia 53, 688-695. doi: 10.1002/ glia. 20328

Bunner, K. D., and Rebec, G. V. (2016). Corticostriatal dysfunction in Huntington's disease: the basics. Front. Hum. Neurosci. 10, 317. doi: 10.3389/ fnhum.2016.00317

Carson, M. J., Thrash, J. C., and Walter, B. (2006). The cellular response in neuroinflammation: The role of leukocytes, microglia and astrocytes in neuronal death and survival. Clin. Neurosci. Res. 6, 237-245. doi: 10.1016/j. cnr.2006.09.004

Caselli, R. J., Beach, T. G., Knopman, D. S., and Graff-Radford, N. R. (2017) Alzheimer disease: scientific breakthroughs and translational challenges. Mayo. Clin. Proc. 92, 978-994. doi: 10.1016/j.mayocp.2017.02.011

Chen, A., Akinyemi, R. O., Hase, Y., Firbank, M. J., Ndung'u, M. N., Foster, V., et al. (2016). Frontal white matter hyperintensities, clasmatodendrosis and gliovascular abnormalities in ageing and post-stroke dementia. Brain 139, 242-258. doi: 10.1093/brain/awv328

Choudhury, G. R., and Ding, S. (2016). Reactive astrocytes and therapeutic potential in focal ischemic stroke. Neurobiol. Dis 85, 234-244. doi: 10.1016/j. nbd.2015.05.003

Chu, K., Lee, S. T., Sinn, D. I., Ko, S. Y., Kim, E. H., Kim, J. M., et al. (2007). Pharmacological induction of ischemic tolerance by glutamate transporter-1 (EAAT2) upregulation. Stroke 38, 177-182. doi: 10.1161/01. STR.0000252091.36912.65 
Cirillo, C., Capoccia, E., Iuvone, T., Cuomo, R., Sarnelli, G., Steardo, L., et al. (2015). S100B inhibitor pentamidine attenuates reactive gliosis and reduces neuronal loss in a mouse model of Alzheimer's disease. Biomed. Res. Int. 2015, 11. doi: $10.1155 / 2015 / 508342$

Clark, W. M., and Lutsep, H. L. (2001). Potential of anticytokine therapies in central nervous system ischaemia. Expert. Opin. Biol. Ther. 1, 227-237. doi: 10.1517/14712598.1.2.227

Colombo, E., and Farina, C. (2016). Astrocytes: key regulators of neuroinflammation. Trends Immunol. 37, 608-620. doi: 10.1016/j.it.2016.06.006

Colton, C. K., Kong, Q., Lai, L., Zhu, M. X., Seyb, K. I., Cuny, G. D., et al. (2010). Identification of translational activators of glial glutamate transporter EAAT2 through cell-based high-throughput screening: an approach to prevent excitotoxicity. J. Biomol. Screen. 15, 653-662. doi: 10.1177/1087057110370998

Combs, C. K., Johnson, D. E., Karlo, J. C., Cannady, S. B., and Landreth, G. E. (2000). Inflammatory mechanisms in Alzheimer's disease: inhibition of beta-amyloid-stimulated proinflammatory responses and neurotoxicity by PPARgamma agonists. J. Neurosci. 20, 558-567. doi: 10.1523/ JNEUROSCI.20-02-00558.2000

Crunelli, V., Carmignoto, G., and Steinhauser, C. (2015). Novel astrocyte targets: new avenues for the therapeutic treatment of epilepsy. Neuroscientist 21, 62-83. doi: 10.1177/1073858414523320

Cuevas, E., Limon, D., Perez-Severiano, F., Diaz, A., Ortega, L., Zenteno, E., et al. (2009). Antioxidant effects of epicatechin on the hippocampal toxicity caused by amyloid-beta 25-35 in rats. Eur. J. Pharmacol. 616, 122-127. doi: 10.1016/j. ejphar.2009.06.013

De Nuccio, C., Bernardo, A., Cruciani, C., De Simone, R., Visentin, S., and Minghetti, L. (2015). Peroxisome proliferator activated receptor-gamma agonists protect oligodendrocyte progenitors against tumor necrosis factoralpha-induced damage: effects on mitochondrial functions and differentiation. Exp. Neurol. 271, 506-514. doi: 10.1016/j.expneurol.2015.07.014

De Zeeuw, C. I., and Hoogland, T. M. (2015). Reappraisal of Bergmann glial cells as modulators of cerebellar circuit function. Front. Cell Neurosci. 9, 246. doi: $10.3389 /$ fncel.2015.00246

Ding, S. H., Wang, T. N., Cui, W. J., and Haydon, P. G. (2009). Photothrombosis ischemia stimulates a sustained astrocytic Ca2+ signaling in vivo. Glia 57, 767776. doi: 10.1002/glia.20804

Dong, Y. S., and Benveniste, E. N. (2001). Immune function of astrocytes. Glia 36, 180-190. doi: 10.1002/glia.1107

Farfara, D., Lifshitz, V., and Frenkel, D. (2008). Neuroprotective and neurotoxic properties of glial cells in the pathogenesis of Alzheimer's disease. J. Cell Mol. Med. 12, 762-780. doi: 10.1111/j.1582-4934.2008.00314.x

Finsterwald, C., Magistretti, P. J., and Lengacher, S. (2015). Astrocytes: new targets for the treatment of neurodegenerative diseases. Curr. Pharm. Des. 21, 35703581. doi: 10.2174/1381612821666150710144502

Fisher, R. S., Van Emde Boas, W., Blume, W., Elger, C., Genton, P., Lee, P., et al. (2005). Epileptic seizures and epilepsy: definitions proposed by the International League Against Epilepsy (ILAE) and the International Bureau for Epilepsy (IBE). Epilepsia 46, 470-472. doi: 10.1111/j.0013-9580.2005.66104.x

French, J. A., and Gazzola, D. M. (2011). New generation antiepileptic drugs: what do they offer in terms of improved tolerability and safety? Ther. Adv. Drug Saf. 2, 141-158. doi: 10.1177/2042098611411127

Frizzo, M. E., Dall'onder, L. P., Dalcin, K. B., and Souza, D. O. (2004). Riluzole enhances glutamate uptake in rat astrocyte cultures. Cell Mol. Neurobiol. 24, 123-128. doi: 10.1023/B:CEMN.0000012717.37839.07

Gajardo-Gomez, R., Labra, V. C., Maturana, C. J., Shoji, K. F., Santibanez, C. A., Saez, J. C., et al. (2017). Cannabinoids prevent the amyloid beta-induced activation of astroglial hemichannels: a neuroprotective mechanism. Glia 65, 122-137. doi: 10.1002/glia.23080

Garwood, C., Ratcliffe, L., Simpson, J., Heath, P., Ince, P., and Wharton, S. (2017). Astrocytes in Alzheimer's disease and other age-associated dementias: a supporting player with a central role. Neuropathol. Appl. Neurobiol. 43, 281298. doi: 10.1111/nan.12338

Giralt, A., Friedman, H., Caneda-Ferron, B., Urban, N., Moreno, E., Rubio, N., et al. (2010). BDNF regulation under GFAP promoter provides engineered astrocytes as a new approach for long-term protection in Huntington's disease. Gene Ther. 17, 1294. doi: 10.1038/gt.2010.71

Giri, R., Shen, Y., Stins, M., Du Yan, S., Schmidt, A. M., Stern, D., et al. (2000). $\beta$-Amyloid-induced migration of monocytes across human brain endothelial cells involves RAGE and PECAM-1. Am. J. Physiol. Cell Physiol. 279, C1772C1781. doi: 10.1152/ajpcell.2000.279.6.C1772

Goldberg, E. M., and Coulter, D. A. (2013). Mechanisms of epileptogenesis: a convergence on neural circuit dysfunction. Nat. Rev. Neurosci. 14, 337-349. doi: $10.1038 / \mathrm{nrn} 3482$

Gomez-Gonzalo, M., Losi, G., Chiavegato, A., Zonta, M., Cammarota, M., Brondi, M., et al. (2010). An excitatory loop with astrocytes contributes to drive neurons to seizure threshold. PLoS Biol. 8, e1000352. doi: 10.1371/journal.pbio.1000352

González-Reyes, R. E., Nava-Mesa, M. O., Vargas-Sánchez, K., Ariza-Salamanca, D., and Mora-Muñoz, L. (2017). Involvement of astrocytes in Alzheimer's disease from a neuroinflammatory and oxidative stress perspective. Front. Mol. Neurosci. 10, 427. doi: 10.3389/fnmol.2017.00427

Haughey, N. J., and Mattson, M. P. (2003). Alzheimer's amyloid $\beta$-peptide enhances ATP/gap junction-mediated calcium-wave propagation in astrocytes. Neuromolecular Med. 3, 173-180. doi: 10.1385/NMM:3:3:173

Hong, Y., Zhao, T., Li, X.-J., and Li, S. (2016). Mutant huntingtin impairs BDNF release from astrocytes by disrupting conversion of Rab3a-GTP into Rab3aGDP. J. Neurosci. 36, 8790-8801. doi: 10.1523/JNEUROSCI.0168-16.2016

Hong, Y., Zhao, T., Li, X.-J., and Li, S. (2017). Mutant huntingtin inhibits aB-crystallin expression and impairs exosome secretion from astrocytes. $J$. Neurosci. 37, 9550-9563. doi: 10.1523/JNEUROSCI.1418-17.2017

Huang, X., Zhang, H., Yang, J., Wu, J., Mcmahon, J., Lin, Y., et al. (2010). Pharmacological inhibition of the mammalian target of rapamycin pathway suppresses acquired epilepsy. Neurobiol. Dis 40, 193-199. doi: 10.1016/j. nbd.2010.05.024

Ibrahim, N. F., Yanagisawa, D., Durani, L. W., Hamezah, H. S., Damanhuri, H. A., Wan Ngah, W. Z., et al. (2017). Tocotrienol-Rich fraction modulates amyloid pathology and improves cognitive function in AbetaPP/PS1 mice. J. Alzheimers Dis. 55, 597-612. doi: 10.3233/JAD-160685

Jansen, A. H., Van Hal, M., Op Den Kelder, I. C., Meier, R. T., De Ruiter, A. A., Schut, M. H., et al. (2017). Frequency of nuclear mutant huntingtin inclusion formation in neurons and glia is cell-type-specific. Glia 65, 50-61. doi: 10.1002/ glia. 23050

Jaradat, M. S., Wongsud, B., Phornchirasilp, S., Rangwala, S. M., Shams, G., Sutton, M., et al. (2001). Activation of peroxisome proliferator-activated receptor isoforms and inhibition of prostaglandin $\mathrm{H}(2)$ synthases by ibuprofen, naproxen, and indomethacin. Biochem. Pharmacol. 62, 1587-1595. doi: 10.1016/S0006-2952(01)00822-X

Jeong, J. C., Yoon, C. H., Lee, W. H., Park, K. K., Chang, Y. C., Choi, Y. H., et al. (2005). Effects of Bambusae concretio Salicea (Chunchukhwang) on amyloid beta-induced cell toxicity and antioxidative enzymes in cultured rat neuronal astrocytes. J. Ethnopharmacol. 98, 259-266. doi: 10.1016/j.jep.2004.12.034

Ji, Y. F., Xu, S. M., Zhu, J., Wang, X. X., and Shen, Y. (2011). Insulin increases glutamate transporter GLT1 in cultured astrocytes. Biochem. Biophys. Res. Commun. 405, 691-696. doi: 10.1016/j.bbrc.2011.01.105

Jiang, R., Diaz-Castro, B., Looger, L. L., and Khakh, B. S. (2016). Dysfunctional calcium and glutamate signaling in striatal astrocytes from Huntington's disease model mice. J. Neurosci. 36, 3453-3470. doi: 10.1523/JNEUROSCI.3693-15.2016

Jo, S., Yarishkin, O., Hwang, Y. J., Chun, Y. E., Park, M., Woo, D. H., et al. (2014). GABA from reactive astrocytes impairs memory in mouse models of Alzheimer's disease. Nat. Med. 20, 886-896. doi: 10.1038/nm.3639

Justicia, C., Perez-Asensio, F. J., Burguete, M. C., Salom, J. B., and Planas, A. M. (2001). Administration of transforming growth factor-alpha reduces infarct volume after transient focal cerebral ischemia in the rat. J. Cereb. Blood Flow Metab. 21, 1097-1104. doi: 10.1097/00004647-200109000-00007

Khakh, B. S., Beaumont, V., Cachope, R., Munoz-Sanjuan, I., Goldman, S. A., and Grantyn, R. (2017). Unravelling and exploiting astrocyte dysfunction in Huntington's disease. Trends Neurosci. 40, 422-437. doi: 10.1016/j. tins.2017.05.002

Khakh, B. S., and Sofroniew, M. V. (2014). Astrocytes and Huntington's disease. ACS Chem. Neurosci. 5, 494-496. doi: 10.1021/cn500100r

Khakh, B. S., and Sofroniew, M. V. (2015). Diversity of astrocyte functions and phenotypes in neural circuits. Nat. Neurosci. 18, 942. doi: 10.1038/nn.4043

Kim, J. K., and Lee, J. H. (2019). Mechanistic target of rapamycin pathway in epileptic disorders. J. Korean Neurosurg. Soc. 62, 272-287. doi: 10.3340/ jkns.2019.0027

Kim, J. S. (1996). Cytokines and adhesion molecules in stroke and related diseases. J. Neurol. Sci. 137, 69-78. doi: 10.1016/0022-510X(95)00338-3 
Kim, Y. E., Hwang, C. J., Lee, H. P., Kim, C. S., Son, D. J., Ham, Y. W., et al. (2017). Inhibitory effect of punicalagin on lipopolysaccharide-induced neuroinflammation, oxidative stress and memory impairment via inhibition of nuclear factor-kappaB. Neuropharmacology 117, 21-32. doi: 10.1016/j. neuropharm.2017.01.025

Kitazawa, M., Cheng, D., Tsukamoto, M. R., Koike, M. A., Wes, P. D., Vasilevko, V., et al. (2011). Blocking IL-1 signaling rescues cognition, attenuates tau pathology, and restores neuronal beta-catenin pathway function in an Alzheimer's disease model. J. Immunol. 187, 6539-6549. doi: 10.4049/jimmunol.1100620

Kong, Q., Chang, L. C., Takahashi, K., Liu, Q., Schulte, D. A., Lai, L., et al. (2014). Small-molecule activator of glutamate transporter EAAT2 translation provides neuroprotection. J. Clin. Invest. 124, 1255-1267. doi: 10.1172/JCI66163

Kwan, P., and Brodie, M. J. (2000). Early identification of refractory epilepsy. $N$. Engl. J. Med. 342, 314-319. doi: 10.1056/NEJM200002033420503

Lee, E. S., Sidoryk, M., Jiang, H., Yin, Z., and Aschner, M. (2009). Estrogen and tamoxifen reverse manganese-induced glutamate transporter impairment in astrocytes. J. Neurochem. 110, 530-544. doi: 10.1111/j.1471-4159.2009.06105.x

Li, J. M., Zhang, Y., Tang, L., Chen, Y. H., Gao, Q., Bao, M. H., et al. (2016). Effects of triptolide on hippocampal microglial cells and astrocytes in the APP/PS1 double transgenic mouse model of Alzheimer's disease. Neural Regen. Res. 11, 1492-1498. doi: 10.4103/1673-5374.191224

Li, L., Zhang, H., Varrin-Doyer, M., Zamvil, S. S., and Verkman, A. S. (2011). Proinflammatory role of aquaporin-4 in autoimmune neuroinflammation. FASEB J. 25, 1556-1566. doi: 10.1096/fj.10-177279

Libro, R., Giacoppo, S., Soundara Rajan, T., Bramanti, P., and Mazzon, E. (2016). Natural Phytochemicals in the treatment and prevention of dementia: an overview. Molecules 21, 518. doi: 10.3390/molecules21040518

Liddelow, S. A., Guttenplan, K. A., Clarke, L. E., Bennett, F. C., Bohlen, C. J., Schirmer, L., et al. (2017). Neurotoxic reactive astrocytes are induced by activated microglia. Nature 541, 481. doi: 10.1038/nature21029

Lim, D., Iyer, A., Ronco, V., Grolla, A. A., Canonico, P. L., Aronica, E., et al. (2013). Amyloid beta deregulates astroglial mGluR5-mediated calcium signaling via calcineurin and Nf-kB. Glia 61, 1134-1145. doi: 10.1002/glia.22502

Liu, Z., and Chopp, M. (2016). Astrocytes, therapeutic targets for neuroprotection and neurorestoration in ischemic stroke. Prog. Neurobiol. 144, 103-120. doi: 10.1016/j.pneurobio.2015.09.008

Luo, C., Yi, B., Fan, W., Chen, K., Gui, L., Chen, Z., et al. (2011). Enhanced angiogenesis and astrocyte activation by ecdysterone treatment in a focal cerebral ischemia rat model. Acta Neurochir. Suppl. 110, 151-155. doi: 10.1007/978-3-7091-0353-1_26

Mackic, J. B., Stins, M., Mccomb, J. G., Calero, M., Ghiso, J., Kim, K. S., et al. (1998). Human blood-brain barrier receptors for Alzheimer's amyloid-beta 1-40. Asymmetrical binding, endocytosis, and transcytosis at the apical side of brain microvascular endothelial cell monolayer. J. Clin. Invest. 102, 734-743. doi: 10.1172/JCI2029

Mandrekar-Colucci, S., Karlo, J. C., and Landreth, G. E. (2012). Mechanisms underlying the rapid peroxisome proliferator-activated receptor-gammamediated amyloid clearance and reversal of cognitive deficits in a murine model of Alzheimer's disease. J. Neurosci. 32, 10117-10128. doi: 10.1523/ JNEUROSCI.5268-11.2012

Masliah, E., Hansen, L., Alford, M., Deteresa, R., and Mallory, M. (1996). Deficient glutamate tranport is associated with neurodegeneration in Alzheimer's disease. Ann. Neurol. 40, 759-766. doi: 10.1002/ana.410400512

Medvedeva, Y. V., Lin, B., Shuttleworth, C. W., and Weiss, J. H. (2009). Intracellular $\mathrm{Zn} 2+$ accumulation contributes to synaptic failure, mitochondrial depolarization, and cell death in an acute slice oxygen-glucose deprivation model of ischemia. J. Neurosci. 29, 1105-1114. doi: 10.1523/ JNEUROSCI.4604-08.2009

Merienne, N., Delzor, A., Viret, A., Dufour, N., Rey, M., Hantraye, P., et al. (2015). Gene transfer engineering for astrocyte-specific silencing in the CNS. Gene Ther. 22, 830-839. doi: 10.1038/gt.2015.54

Merlini, M., Meyer, E. P., Ulmann-Schuler, A., and Nitsch, R. M. (2011). Vascular $\beta$-amyloid and early astrocyte alterations impair cerebrovascular function and cerebral metabolism in transgenic arcA $\beta$ mice. Acta Neuropathol. 122, 293311. doi: 10.1007/s00401-011-0834-y

Monje, M. L., Toda, H., and Palmer, T. D. (2003). Inflammatory blockade restores adult hippocampal neurogenesis. Science 302, 1760-1765. doi: 10.1126/ science. 1088417
Mosconi, L., Sorbi, S., De Leon, M. J., Li, Y., Nacmias, B., Myoung, P. S., et al. (2006). Hypometabolism exceeds atrophy in presymptomatic early-onset familial Alzheimer's disease. J. Nucl. Med. 47, 1778-1786.

Ouyang, Y. B., Voloboueva, L. A., Xu, L. J., and Giffard, R. G. (2007). Selective dysfunction of hippocampal CA1 astrocytes contributes to delayed neuronal damage after transient forebrain ischemia. J. Neurosci. 27, 4253-4260. doi: 10.1523/JNEUROSCI.0211-07.2007

Ouyang, Y. B., Xu, L., Lu, Y., Sun, X., Yue, S., Xiong, X. X., et al. (2013). Astrocyteenriched miR-29a targets PUMA and reduces neuronal vulnerability to forebrain ischemia. Glia 61, 1784-1794. doi: 10.1002/glia.22556

Ouyang, Y. B., Xu, L., Yue, S., Liu, S., and Giffard, R. G. (2014). Neuroprotection by astrocytes in brain ischemia: importance of microRNAs. Neurosci. Lett. 565, 53-58. doi: 10.1016/j.neulet.2013.11.015

Pandolfo, M. (2011). Genetics of epilepsy. Semin. Neurol. 31, 506-518. doi: 10.1055/s-0031-1299789

Parsons, M. P., Vanni, M. P., Woodard, C. L., Kang, R., Murphy, T. H., and Raymond, L. A. (2016). Real-time imaging of glutamate clearance reveals normal striatal uptake in Huntington disease mouse models. Nat. Commun. 7, 11251. doi: 10.1038/ncomms 11251

Patel, N. S., Paris, D., Mathura, V., Quadros, A. N., Crawford, F. C., and Mullan, M. J. (2005). Inflammatory cytokine levels correlate with amyloid load in transgenic mouse models of Alzheimer's disease. J. Neuroinflammation 2, 9. doi: 10.1186/1742-2094-2-9

Peteri, U.-K., Niukkanen, M., and Castrén, M. L. (2019). Astrocytes in neuropathologies affecting the frontal cortex. Front. Cell Neurosci. 13, 44. doi: $10.3389 /$ fncel.2019.00044

Prevot, V., Dehouck, B., Sharif, A., Ciofi, P., Giacobini, P., and Clasadonte, J. (2018). The versatile tanycyte: a hypothalamic integrator of reproduction and energy metabolism. Endocr. Rev. 39, 333-368. doi: 10.1210/er.2017-00235

Rehman, S. U., Shah, S. A., Ali, T., Chung, J. I., and Kim, M. O. (2017). Anthocyanins reversed D-galactose-induced oxidative stress and neuroinflammation mediated cognitive impairment in adult rats. Mol. Neurobiol. 54, 255-271. doi: 10.1007/s12035-015-9604-5

Reick, C., Ellrichmann, G., Tsai, T., Lee, D.-H., Wiese, S., Gold, R., et al. (2016). Expression of brain-derived neurotrophic factor in astrocytesbeneficial effects of glatiramer acetate in the R6/2 and YAC128 mouse models of Huntington's disease. Exp. Neurol. 285, 12-23. doi: 10.1016/j. expneurol.2016.08.012

Reiman, E. M., Chen, K., Alexander, G. E., Caselli, R. J., Bandy, D., Osborne, D., et al. (2004). Functional brain abnormalities in young adults at genetic risk for late-onset Alzheimer's dementia. Proc. Natl. Acad. Sci. 101, 284-289. doi: 10.1073/pnas. 2635903100

Roberts, R. C., Roche, J. K., and Mccullumsmith, R. E. (2014). Localization of excitatory amino acid transporters EAAT1 and EAAT2 in human postmortem cortex: a light and electron microscopic study. Neuroscience 277, 522-540. doi: 10.1016/j.neuroscience.2014.07.019

Rossi, D., and Volterra, A. (2009). Astrocytic dysfunction: insights on the role in neurodegeneration. Brain Res. Bull. 80, 224-232. doi: 10.1016/j. brainresbull.2009.07.012

Rothstein, J. D., Patel, S., Regan, M. R., Haenggeli, C., Huang, Y. H., Bergles, D. E., et al. (2005). Beta-lactam antibiotics offer neuroprotection by increasing glutamate transporter expression. Nature 433, 73-77. doi: 10.1038/ nature 03180

Russo, E., Follesa, P., Citraro, R., Camastra, C., Donato, A., Isola, D., et al. (2014). The mTOR signaling pathway and neuronal stem/progenitor cell proliferation in the hippocampus are altered during the development of absence epilepsy in a genetic animal model. Neurol. Sci. 35, 1793-1799. doi: 10.1007/ s10072-014-1842-1

Sassone, J., Papadimitriou, E., and Thomaidou, D. (2018). Regenerative Approaches in huntington's disease: from mechanistic insights to therapeutic protocols. Front. Neurosci. 12, 800. doi: 10.3389/fnins.2018.00800

Sastre, M., and Gentleman, S. M. (2010). NSAIDs: how they work and their prospects as therapeutics in Alzheimer's disease. Front. Aging Neurosci. 2. doi: $10.3389 /$ fnagi.2010.00020

Saura, J., Luque, J. M., Cesura, A. M., Da Prada, M., Chan-Palay, V., Huber, G., et al. (1994). Increased monoamine oxidase B activity in plaque-associated astrocytes of Alzheimer brains revealed by quantitative enzyme radioautography. Neuroscience 62, 15-30. doi: 10.1016/0306-4522(94)90311-5 
Sharif, A., Legendre, P., Prevot, V., Allet, C., Romao, L., Studler, J. M., et al. (2007). Transforming growth factor alpha promotes sequential conversion of mature astrocytes into neural progenitors and stem cells. Oncogene 26, 2695-2706. doi: 10.1038/sj.onc.1210071

Shen, Y., He, P., Fan, Y. Y., Zhang, J. X., Yan, H. J., Hu, W. W., et al. (2010). Carnosine protects against permanent cerebral ischemia in histidine decarboxylase knockout mice by reducing glutamate excitotoxicity. Free Radic. Biol. Med. 48, 727-735. doi: 10.1016/j.freeradbiomed.2009.12.021

Sherwood, C. C., Stimpson, C. D., Raghanti, M. A., Wildman, D. E., Uddin, M., Grossman, L. I., et al. (2006). Evolution of increased glia-neuron ratios in the human frontal cortex. Proc. Natl. Acad. Sci. 103, 13606-13611. doi: 10.1073/ pnas.0605843103

Shi, Y. C., Pan, T. M., and Liao, V. H. (2016). Monascin from Monascus-fermented products reduces oxidative stress and amyloid-beta toxicity via DAF-16/FOXO in Caenorhabditis elegans. J. Agric. Food Chem. 64, 7114-7120. doi: 10.1021/ acs.jafc.6b02779

Shin, J.-Y., Fang, Z.-H., Yu, Z.-X., Wang, C.-E., Li, S.-H., and Li, X.-J. (2005). Expression of mutant huntingtin in glial cells contributes to neuronal excitotoxicity. J. Cell Biol. 171, 1001-1012. doi: 10.1083/jcb.200508072

Sofroniew, M. (2000). Astrocyte failure as a cause of CNS dysfunction. Mol. Psyciatry 5 (3), 230-232. doi: 10.1038/sj.mp.4000753

Sohanaki, H., Baluchnejadmojarad, T., Nikbakht, F., and Roghani, M. (2016). Pelargonidin improves memory deficit in amyloid beta25-35 rat model of Alzheimer's disease by inhibition of glial activation, cholinesterase, and oxidative stress. Biomed. Pharmacother. 83, 85-91. doi: 10.1016/j. biopha.2016.06.021

Steinhauser, C., and Seifert, G. (2012). "Astrocyte dysfunction in epilepsy," in Jasper's Basic Mechanisms of the Epilepsies. Eds. Th, J.L. Noebels, M. Avoli, M. A. Rogawski, R. W. Olsen, and A. V. Delgado-Escueta(Bethesda (MD): National Center for Biotechnology Information (US)).

Steinhauser, C., Grunnet, M., and Carmignoto, G. (2016). Crucial role of astrocytes in temporal lobe epilepsy. Neuroscience 323, 157-169. doi: 10.1016/j. neuroscience.2014.12.047

Steinhauser, C., Seifert, G., and Bedner, P. (2012). Astrocyte dysfunction in temporal lobe epilepsy: K+ channels and gap junction coupling. Glia 60, $1192-$ 1202. doi: 10.1002/glia.22313

Stewart, C. R., Stuart, L. M., Wilkinson, K., Van Gils, J. M., Deng, J., Halle, A., et al. (2010). CD36 ligands promote sterile inflammation through assembly of a tolllike receptor 4 and 6 heterodimer. Nat. Immunol. 11, 155-161. doi: 10.1038/ ni. 1836

Stoll G., Jander S., and Schroeter M. (1998). Inflammation and glial responses ischemic brain lessions. Prog. Neurobiol. 56 (2), 149-171. doi: 10.1016/ S0301-0082(98)00034-3

Stroth, N., and Svenningsson, P. (2015). S100B interacts with the serotonin 5-HT7 receptor to regulate a depressive-like behavior. Eur. Neuropsychopharmacol. 25, 2372-2380. doi: 10.1016/j.euroneuro.2015.10.003

Taguchi, A., Blood, D. C., Del Toro, G., Canet, A., Lee, D. C., Qu, W., et al. (2000). Blockade of RAGE-amphoterin signalling suppresses tumour growth and metastases. Nature 405, 354. doi: 10.1038/35012626

Talantova, M., Sanz-Blasco, S., Zhang, X., Xia, P., Akhtar, M. W., Okamoto, S.-I., et al. (2013). A $\beta$ induces astrocytic glutamate release, extrasynaptic NMDA receptor activation, and synaptic loss. Proc. Natl. Acad. Sci. 110, E2518-E2527. doi: 10.1073/pnas.1306832110

Tanaka, E., Yamamoto, S., Kudo, Y., Mihara, S., and Higashi, H. (1997). Mechanisms underlying the rapid depolarization produced by deprivation of oxygen and glucose in rat hippocampal CA1 neurons in vitro. J. Neurophysiol. 78, 891-902. doi: 10.1152/jn.1997.78.2.891

Taverna, E., Götz, M., and Huttner, W. B. (2014). The cell biology of neurogenesis: toward an understanding of the development and evolution of the neocortex. Annu. Rev. Cell Dev. Biol. 30, 465-502. doi: 10.1146/ annurev-cellbio-101011-155801

Tian, G., Kong, Q., Lai, L., Ray-Chaudhury, A., and Lin, C. L. G. (2010). Increased expression of cholesterol 24S-hydroxylase results in disruption of glial glutamate transporter EAAT2 association with lipid rafts: a potential role in Alzheimer's disease. J. Neurochem. 113, 978-989. doi: 10.1111/j.1471-4159.2010.06661.x
Tong, X., Ao, Y., Faas, G. C., Nwaobi, S. E., Xu, J., Haustein, M. D., et al. (2014). Astrocyte Kir4. 1 ion channel deficits contribute to neuronal dysfunction in Huntington's disease model mice. Nat. Neurosci. 17, 694. doi: 10.1038/nn.3691

Tweedie, D., Ferguson, R. A., Fishman, K., Frankola, K. A., Van Praag, H., Holloway, H. W., et al. (2012). Tumor necrosis factor-alpha synthesis inhibitor 3,6'-dithiothalidomide attenuates markers of inflammation, Alzheimer pathology and behavioral deficits in animal models of neuroinflammation and Alzheimer's disease. J. Neuroinflammation 9, 106. doi: 10.1186/1742-2094-9-106

Van Der Worp, H. B., and Van Gijn, J. (2007). Clinical practice. Acute ischemic stroke. N. Engl. J. Med. 357, 572-579. doi: 10.1056/NEJMcp072057

Vasile, F., Dossi, E., and Rouach, N. (2017). Human astrocytes: structure and functions in the healthy brain. Brain Struct. Funct. 222, 2017-2029. doi: 10.1007/ s00429-017-1383-5

Verma, R., Mishra, V., Sasmal, D., and Raghubir, R. (2010). Pharmacological evaluation of glutamate transporter 1 (GLT-1) mediated neuroprotection following cerebral ischemia/reperfusion injury. Eur. J. Pharmacol. 638, 65-71. doi: 10.1016/j.ejphar.2010.04.021

Von Bernhardi, R., Tichauer, J. E., and Eugenin, J. (2010). Aging-dependent changes of microglial cells and their relevance for neurodegenerative disorders. J. Neurochem. 112, 1099-1114. doi: 10.1111/j.1471-4159.2009.06537.x

Wang, G., Chen, L., Pan, X., Chen, J., Wang, L., Wang, W., et al. (2016). The effect of resveratrol on beta amyloid-induced memory impairment involves inhibition of phosphodiesterase-4 related signaling. Oncotarget 7, 17380-17392. doi: 10.18632/oncotarget.8041

Wang, J., Shi, Y., Zhang, L., Zhang, F., Hu, X., Zhang, W., et al. (2014). Omega-3 polyunsaturated fatty acids enhance cerebral angiogenesis and provide long-term protection after stroke. Neurobiol. Dis 68, 91-103. doi: 10.1016/j. nbd.2014.04.014

Wang, L., Wang, M., Hu, J., Shen, W., Hu, J., Yao, Y., et al. (2017). Protective effect of 3H-1, 2-dithiole-3-thione on cellular model of Alzheimer's disease involves Nrf2/ARE signaling pathway. Eur. J. Pharmacol. 795, 115-123. doi: 10.1016/j. ejphar.2016.12.013

Wetherington, J., Serrano, G., and Dingledine, R. (2008). Astrocytes in the epileptic brain. Neuron 58, 168-178. doi: 10.1016/j.neuron.2008.04.002

White, H. S., Smith, M. D., and Wilcox, K. S. (2007). Mechanisms of action of antiepileptic drugs. Int. Rev. Neurobiol. 81, 85-110. doi: 10.1016/ S0074-7742(06)81006-8

Wick, M., Hurteau, G., Dessev, C., Chan, D., Geraci, M. W., Winn, R. A., et al. (2002). Peroxisome proliferator-activated receptor-gamma is a target of nonsteroidal anti-inflammatory drugs mediating cyclooxygenase-independent inhibition of lung cancer cell growth. Mol. Pharmacol. 62, 1207-1214. doi: 10.1124/mol.62.5.1207

Wilkinson, K., and El Khoury, J. (2012). Microglial scavenger receptors and their roles in the pathogenesis of Alzheimer's disease. Int. J. Alzheimers Dis. 2012, 10 doi: $10.1155 / 2012 / 489456$

Wyss-Coray, T., and Rogers, J. (2012). Inflammation in Alzheimer disease-a brief review of the basic science and clinical literature. Cold Spring Harb. Perspect. Med. 2, a006346. doi: 10.1101/cshperspect.a006346

Xing, X., Chang, L. C., Kong, Q., Colton, C. K., Lai, L., Glicksman, M. A., et al. (2011). Structure-activity relationship study of pyridazine derivatives as glutamate transporter EAAT2 activators. Bioorg. Med. Chem. Lett. 21, 57745777. doi: 10.1016/j.bmcl.2011.08.009

Xiu, J., Nordberg, A., Zhang, J.-T., and Guan, Z.-Z. (2005). Expression of nicotinic receptors on primary cultures of rat astrocytes and up-regulation of the $\alpha 7, \alpha 4$ and $\beta 2$ subunits in response to nanomolar concentrations of the $\beta$-amyloid peptide1-42. Neurochem. Int. 47, 281-290. doi: 10.1016/j. neuint.2005.04.023

Yan, S. D., Schmidt, A. M., Anderson, G. M., Zhang, J., Brett, J., Zou, Y. S., et al. (1994). Enhanced cellular oxidant stress by the interaction of advanced glycation end products with their receptors/binding proteins. J. Biol. Chem. 269, 9889-9897.

Yi, J.-H., and Hazell, A. S. (2006). Excitotoxic mechanisms and the role of astrocytic glutamate transporters in traumatic brain injury. Neurochem. Int. 48, 394-403. doi: 10.1016/j.neuint.2005.12.001

Yuan, T. F., and Shan, C. (2014). "Glial inhibition" of memory in Alzheimer's disease. Sci. China Life Sci. 57, 1238-1240. doi: 10.1007/s11427-014-4780-5 
Zamanian, J. L., Xu, L. J., Foo, L. C., Nouri, N., Zhou, L., Giffard, R. G., et al. (2012). Genomic analysis of reactive astrogliosis. J. Neurosci. 32, 6391-6410. doi: 10.1523/JNEUROSCI.6221-11.2012

Zhang, X., Wan, J. Q., and Tong, X. P. (2018). Potassium channel dysfunction in neurons and astrocytes in Huntington's disease. CNS Neurosci. Ther. 24, 311318. doi: $10.1111 / \mathrm{cns} .12804$

Zhang, Z. G., and Chopp, M. (2009). Neurorestorative therapies for stroke: underlying mechanisms and translation to the clinic. Lancet Neurol. 8, 491500. doi: 10.1016/S1474-4422(09)70061-4

Zhao, T., Hong, Y., Li, S., and Li, X.-J. (2016). Compartment-dependent degradation of mutant huntingtin accounts for its preferential accumulation in neuronal processes. J. Neurosci. 36, 8317-8328. doi: 10.1523/JNEUROSCI.0806-16.2016

Zhao, T., Hong, Y., Yin, P., Li, S., and Li, X.-J. (2017). Differential HspBP1 expression accounts for the greater vulnerability of neurons than astrocytes to misfolded proteins. Proc. Natl. Acad. Sci. 114, E7803-E7811. doi: 10.1073/ pnas. 1710549114

Zheng, W., Talley Watts, L., Holstein, D. M., Wewer, J., and Lechleiter, J. D. (2013). P2Y1R-initiated, IP3R-dependent stimulation of astrocyte mitochondrial metabolism reduces and partially reverses ischemic neuronal damage in mouse. J. Cereb. Blood Flow Metab. 33, 600-611. doi: 10.1038/ jcbfm.2012.214

Zou, J., Wang, Y.-X., Dou, F.-F., Lü, H.-Z., Ma, Z.-W., Lu, P.-H., et al. (2010). Glutamine synthetase down-regulation reduces astrocyte protection against glutamate excitotoxicity to neurons. Neurochem. Int. 56, 577-584. doi: 10.1016/j.neuint.2009.12.021

Conflict of Interest: The authors declare that the research was conducted in the absence of any commercial or financial relationships that could be construed as a potential conflict of interest.

Copyright (c) 2019 Siracusa, Fusco and Cuzzocrea. This is an open-access article distributed under the terms of the Creative Commons Attribution License (CC BY). The use, distribution or reproduction in other forums is permitted, provided the original author(s) and the copyright owner(s) are credited and that the original publication in this journal is cited, in accordance with accepted academic practice. No use, distribution or reproduction is permitted which does not comply with these terms. 